\title{
O uso de medicamentos no processo de trabalho educativo nas Escolas de Educação Infantil
}

\author{
El uso de medicinas en el proceso de trabajo educativo en los Centros \\ Preescolares
}

\begin{abstract}
1 Janaina Barela Meireles; ${ }^{2}$ Maria Luiza Luongo Silveira; ${ }^{3}$ Leomar Eslabão; ${ }^{4}$ Maria De Fátima Duarte Martins; ${ }^{5}$ Jarbas Santos Vieira

${ }^{1}$ ninameireles234@gmail.com, Universidade Federal de Pelotas; ${ }^{2}$

luiza.luongo@ hotmail.com, Universidade Federal de Pelotas; ${ }^{3}$ el.eslabao@ gmail.com, Instituto Federal Sul Riograndese; ${ }^{4}$ duartemartinsneia@ gmail.com, Universidade Federal de Pelotas; 5jarbas.vieira@gmail.com, Universidade Federal de Pelotas.
\end{abstract}

\begin{abstract}
Resumo
Este texto discute o consumo de medicamentos na rotina de trabalho das professoras e auxiliares que atuam em Escolas Municipais de Educação Infantil de 16 cidades do estado do Rio Grande do Sul. Esse consumo está relacionado às altas exigências e inúmeras demandas que se impõem sobre essas profissionais, que acabam recorrendo ao uso de medicamentos na busca de um reequilíbrio e uma readaptação para manterem-se num nível de bem estar em sua profissão. Os dados foram obtidos através da aplicação de dois instrumentos: o Questionário Sobre o Conteúdo do Trabalho e um Questionário Complementar.
\end{abstract}

Palavras-Chave: intensificação, medicamentação, precarização, presenteísmo, trabalho docente

\section{Introdução}

O objetivo aqui é apresentar os resultados parciais da pesquisa Trabalho e Saúde das Professoras de Educação Infantil das Escolas Públicas Municipais da Região Sul do Rio Grande do Sul. A pesquisa analisa a relação entre a saúde e o processo de trabalho desenvolvido pelas professoras e auxiliares que atuam em Escolas Municipais de Educação Infantil (EMEIs) de 16 cidades da Região Sul do Rio Grande do Sul: Arroio Grande, Arroio do Padre, Canguçu, Capão do Leão, Cerrito, Herval, Cristal, Jaguarão, Morro Redondo, Pedro Osório, Pelotas, Pinheiro Machado, Piratini, Santana da Boa Vista, São Lourenço do Sul, Turuçu.

Autores como ASSUNÇÃO (2009), ESTEVE (1999), HYPOLITO (2009) e VIEIRA et al. (2014) formam a base teórica utilizada para desenvolver esse trabalho e, também, para ampliar os conhecimentos sobre os conceitos de ciclo de medicamentação, mal-estar docente, intensificação e precarização do trabalho docente. Estes conceitos ajudam a ver o quanto o trabalho educativo nas EMEIs vem sendo intensificado - fazer mais coisas no mesmo tempo de trabalho e sob as mesmas condições de infra-estrutura e de apoio pedagógico e social.

\section{Resultados e Discussões}

No decorrer dos anos, as reformas educacionais vêm trazendo novas exigências profissionais para as docentes, embora não tragam consigo condições e adequações necessárias para o desenvolvimento de uma educação de qualidade. Essa realidade acaba 
sendo naturalizada pelas docentes, produzindo um sentimento de que trabalhar sem condições físicas e emocionais faz parte da luta e da doação das professoras.

As docentes que permanecem nas EMEIs, apesar das inúmeras dificuldades que enfrentam, continuam buscando a valorização profissional e acreditam na importância da sua profissão para a sociedade, porém, frente ao desprestígio social que a profissão recebe muitas acabam se acomodando e passam a viver momentos de desânimo, potencializando o adoecimento de muitas delas. Um adoecimento que, muitas vezes, tem levado a categoria ao uso contínuo de medicamentos, o que pode ser chamado de medicamentação, que é a relação entre a adequação das professoras a situações conflituosas no seu trabalho e as tentativas de atenuar os efeitos prejudiciais dessas condições sobre a sua saúde através do consumo de medicamentos.

O consumo de medicamentos pode ser uma forma de silenciar problemas que existem no cotidiano das escolas, o que implica riscos para a saúde de cada docente. Vejamos os dados obtidos.

Questão número 6 do Questionário Complementar:

Para lidar com a rotina de trabalho estou tomando alguma medicação? Nessa questão obteve-se um total de 603 respondentes, que dentre as alternativas não, sim e às vezes responderam $53,4 \%, 24,5 \%$ e $22,1 \%$ respectivamente. Considerando os casos em que foi indicado o uso de algum medicamento de forma contínua ou de forma esporádica, tem-se um percentual bastante significativo e preocupante: $46,6 \%$ das respondentes tomam medicamentos para enfrentar a rotina de trabalho.

Questão número 7 do Questionário Complementar:

Indique os tipos de medicamento que você toma ou já tomou para dar aulas (uma ou mais opções): analgésicos 59\%, antidepressivos 22,2\%, calmantes $13,7 \%$, anti-inflamatórios $41,9 \%$, anti-alérgicos $22,7 \%$, reguladores de humor $5,8 \%$, antibióticos $31,7 \%$, vitaminas $20,4 \%$, outros medicamentos $11,7 \%$ (esses percentuais dizem respeito ao número de vezes que cada medicamento foi assinalado e não ao número de respondes).

De toda forma, esses percentuais por tipo de medicamento fazem ver que essas trabalhadoras - pelo menos 46,6\% delas - podem estar encontrando condições pouco favoráveis no seu processo de trabalho. Tendo em vista que o centro do trabalho na Educação Infantil é o cuidado com as crianças pequenas, implicando relações afetivas e pedagógicas específicas, há de se considerar que uma parte significativa do grupo de trabalhadoras encontra algum impedimento para a realização satisfatória desse processo.

\section{Conclusões}

As novas exigências profissionais e a intensificação do trabalho docente acabam produzindo efeitos sobre a saúde do professorado. Pode-se destacar fatores qualitativos, que são caracterizados pelas transformações da atividade sem o necessário suporte social para acomodar as exigências do trabalho, como também, fatores quantitativos, relacionados ao aumento do volume de tarefas nas escolas. Com isso, é através do uso de medicamentos que as professoras procuram minimizar efeitos prejudiciais que as condições de trabalho trazem para a sua saúde.

No dia-dia das salas de aulas surgem vários conflitos que não são previstos pelo sistema educacional e assim, as professoras se deparam com situações que não estavam preparadas para resolver ou enfrentar. As condições em que trabalham, somado aos baixos salários, a intensificação e o pouco prestígio que recebem, levam muitas profissionais ao adoecimento e, muitas vezes, ao afastamento devido ao mal-estar que sentem em sua profissão. 
É importante dizer que o uso de medicamentos provoca também o presenteísmo, uma vez que muitas professoras, mesmo em situações de adoecimento, permanecem no âmbito escolar, talvez como uma necessidade de se sentirem úteis na sua "missão de educar".

Nesse processo de uso de medicamentos para aliviar os efeitos das condições de trabalho desfavoráveis, pode-se identificar o surgimento de um ciclo da medicamentação, produzindo cada vez mais a necessidade do uso de drogas para permanência no local de trabalho. Desta forma, a pesquisa ainda necessita buscar, de modo mais detalhado, as situações em que o professorado recorre ao uso de medicamentos, sua relação com a automedicação ou com o acompanhamento médico, assim como identificar, mais especificamente, as situações que causam a necessidade de tal consumo.

Por fim, cabe destacar que todos esses conflitos somados ao processo de intensificação, colocam em risco tanto a qualidade da educação quanto a saúde dessas trabalhadoras.

\section{Referências}

ASSUNÇÃO, Ada Ávila. Ensinar em condições precárias: efeitos sobre a saúde; relatório de estudo exploratório. Belo Horizonte: Universidade Federal de Minas Gerais, 2005.

ASSUNÇÃO, Ada Ávila; OLIVEIRA, Dalila Andrade. Intensificação do Trabalho e Saúde dos Professores. Educação \& Sociedade, Campinas, vol. 30, n. 107, p. 349-372, maio/ago. 2009.

BALINHAS, Vera Lúcia Gainssa; VIEIRA, Jarbas Santos; MARTINS, Maria de Fátima Duarte; GARCIA, Maria Manuela Alves; ESLABÃO, Leomar; SILVA, Aline Ferraz da; FETTER, Carmem Lúcia; GONÇALVES, Vanessa Bugs. Imagens da Docência: Um Estudo sobre o Processo de Trabalho e Mal-estar Docente. Revista Mal-estar e Subjetividade, Fortaleza, Vol. XIII - No 12, p. 249-270, mar./jun., 2013.

ESTEVE, José S. O Mal-estar Docente. Bauru, São Paulo: EDUSC, 1999.

HYPOLITO, Álvaro Moreira; VIEIRA, Jarbas dos Santos; PIZZI, Laura Cristina Vieira. Reestruturação Curricular e Auto-intensificação do Trabalho Docente. Currículo Sem Fronteiras, V. 9, n. 2, pp. 100-102, jul/dez 2009.

KARASEK, Robert. Job Content Questionnaire user's guide. Lowell: University of Massachusetts; 1985.

VIEIRA, Jarbas Santos; FONSECA, Márcia Souza. Natureza do Trabalho Docente. DICIONÁRIO: trabalho, profissão e condição docente. Belo Horizonte: UFMG/Faculdade de Educação, 2010. CDROM.

VIEIRA, Jarbas Santos et al. Processo de trabalho das professoras de educação infantil: entre imagens de bondade e o mal-estar docente. Pelotas: UFPEL, 2014. (mimeo., artigo no prelo). 